subsidy to medical schools he provisionally-and perhaps provocatively - proposed that a "franchise" system might be instituted.

The proposal would be that a senior forensic pathologist in each area would be appointed by the Home Office on the advice of the local coroners, chief constables, regional medical officer, and perhaps others to provide forensic pathology services to the local police forces. Perhaps five such areas might cover England and Wales excluding London. These appointments would be made for a fixed term, 5-10 years, on the basis of a "bid" submitted by the appointee, who might be either an academic forensic pathologist or an NHS consultant with forensic interests. This appointee or contractor would then negotiate with his university or hospital to provide space, technical, and secretarial services, as well as subcontracting with other pathologists in the area to help with the case load.

How the scheme could benefit or commend itself to a district general hospital of the NHS is not clear, but there would be distinct advantages for the financially hard pressed universities, which could shed the burden of salaries and running costs for their forensic departments yet maintain some teaching and research. In places such as Manchester and Bristol, which have already lost their departments, the scheme might be a means of reviving defunct facilities.

This plan, reminiscent of the franchise relationship of the various independent television companies to the Independent Broadcasting Authority, accords well with the economic philosophy of the present government. The costs of the service component would be transferred from the University Grants Committee to the prime users, the Home Office, who in turn would stop paying the current $£ 1685$ retaining fee and the call out and milage costs, replacing these by an annual contract payment. The obvious desire at the Home Office for accountability and quality control would be fulfilled by the fixed term franchise, which would not be renewed if the contracting pathologist failed to discharge his duties in what the Home Office considered to be a satisfactory manner.

The whole proposition is certainly better than the current decline into oblivion which otherwise seems to face academic forensic medicine. But Mr Wasserman's audience at Sheffield retained a healthy scepticism, especially about the insecurity of tenure, the relation to NHS linked salary scales, superannuation and distinction awards, and the provision of services where no medical school with forensic representation exists within a designated area. And if the local academic loses the franchise, who else can offer an alternative bid? With regard to "quality control," it was pointed out that a forensic pathologist endures the sternest form of inquiry in the land-namely, cross examination in the witness box.

"Law and order" has recently become a prominent issue-and one much talked about by politicians. Those same politicians might reasonably be asked what steps the government is taking to resuscitate forensic medicine after years of neglect. At last there seems to be a consensus that resuscitation is needed; the government now has to take a very simple decision. Should the public money needed to rebuild forensic medicine come from the purse of the University Grants Committee, the Department of Health and Social Security, or the Home Office?

BERNARD KNIGHT

Professor of Forensic Pathology,

Institute of Pathology,

Royal Infirmary,

Cardiff CF4 1SZ

\section{The treatment of severe falciparum malaria}

Last year nearly 2000 cases of malaria, including over 700 with Plasmodium falciparum, were recorded in the Malaria Reference Laboratory from England and Wales. Whereas vivax malaria has been responsible for most imported infections in recent years, the proportion due to the malignant tertian parasite has increased year by year, even from the Indian subcontinent. Six of the patients with falciparum malaria died in 1984. With the increasing spread of drug resistant strains of this parasite and the dramatic rise in tourism to countries where malaria is endemic doctors in Britain seem likely to see ever more patients with this dangerous infection. A high index of suspicion is the first essential in making the diagnosis, but the correct preparation and examination of thick and thin blood films are of paramount importance. Left untreated, infection with $P$ falciparum in a non-immune person rapidly progresses to produce a fulminating parasitaemia with a cascade of dire pathophysiological consequences, including cerebral malaria, acute intravascular haemolysis, and renal failure. Severe falciparum malaria ("malignant tertian" is a well justified term) is a medical emergency demanding skilled treatment in the intensive care unit.

Irrespective of the geographical origin of the infection or the likely response of the parasites to drugs, the imperatives are, firstly, to reduce the parasitaemia as rapidly as possible without killing the patient from drug toxicity, and, secondly, to provide whatever life supporting measures may be indicated. The introduction of exchange blood transfusion was an important advance in treatment. ${ }^{1}$ We believe that patients with severe falciparum malaria need 5-10 units of blood cross matched on admission and that exchange transfusion should be considered, especially if the parasitaemia is over $10 \%$ (p 1169). In all cases a rapidly acting schizonticide must be given, preferably by intravenous infusion. In patients from Africa quinine dihydrochloride in a dose up to $10 \mathrm{mg}$ base/kg every 12 hours for several infusions is effective in producing a steady fall in parasitaemia with clinical improvement and without serious toxicity ${ }^{2}$ (A P Hall, D N Bhattacharya, unpublished observations).

In Thailand partial resistance to quinine is becoming more common. ${ }^{3}$ White and Warrell and their team showed that a loading dose of $20 \mathrm{mg}$ quinine dihydrochloride per $\mathrm{kg}$ (equivalent to $16.7 \mathrm{mg}$ quinine base $/ \mathrm{kg}$ ) infused over four hours rapidly produced an effective schizonticidal concentration in the blood, and they claimed a more satisfactory clinical response. ${ }^{4}$ Their maintenance dose is $10 \mathrm{mg} / \mathrm{kg}$ of the salt every eight hours until the patient's condition permits continuing treatment by mouth. In their earlier study without a loading dose, however, they reported a death rate of $17 \%$ in cerebral malaria, ${ }^{5}$ while in two subsequent studies of cerebral malaria they reported death rates of $22 \%(33 / 151)$ and $33 \%(15 / 45)$ in patients receiving a loading dose, ${ }^{67}$ so they have not shown that the loading dose of quinine reduces the case fatality rate. The same team claims that $5 \%$ dextrose rather than physiological saline is preferable since severe falciparum parasitaemia itself may lead to hypoglycaemiaand quinine, by stimulating insulin secretion, may further aggravate the condition. ${ }^{8}$ Indeed, they claim that $10 \%$ dextrose infusion may be required rather than $5 \% .^{9}$ In the studies quoted above, however, using smaller doses of 
quinine, severe hypoglycaemia was not detected (p 1169) (Hall and Bhattacharya, unpublished).

Quinidine has long been recognised to be at least as good a blood schizonticide as quinine. Recent studies in Thailand have shown both that this drug (the D-enantiomer of quinine) is severalfold more active than quinine against $P$ falciparum in vitro and that it may replace it for the treatment of uncomplicated infections (P Suntharasamai, S Vanijanond, $\mathrm{T}$ Harinasuta, et al, paper presented at 11 th international congress of tropical medicine and malaria, Calgary, Canada, 1984). ${ }^{10}$ The theoretical objection to quinidine is that it causes a greater prolongation of the Q-T interval than quinine, " but it may be used to treat severe falciparum malaria. ${ }^{12}{ }^{13}$ Again in Thailand, White and his team recommended a loading dose of quinidine of $15 \mathrm{mg}$ base $/ \mathrm{kg}$ followed by $7.5 \mathrm{mg}$ base $/ \mathrm{kg}$ every eight hours. ${ }^{13}$ They have not, however, done a controlled study of intravenous quinine and intravenous quinidine. Quinine in the non-toxic doses used should normally be given for severe falciparum infections from areas other than Thailand $(\mathrm{p} \mathrm{1169})^{2}$ (Hall and Bhattacharya, unpublished). Quinidine in equivalent doses should be used if quinine is not available in the hospital pharmacy. Preliminary reports suggest that an even more rapid schizonticidal response may follow the infusion of artesunate, a soluble derivative of the Chinese compound artemisinin. ${ }^{14}$ There were 960 patients with falciparum malaria from Africa treated in Britain between 1983 and 1984 but only one patient from Thailand (Malaria Reference Laboratory reports).

Supportive management of the life threatening complications of severe falciparum malaria include the reduction of hyperpyrexia, control of convulsions if present, exchange blood transfusion mentioned above, haemodialysis for anuric renal failure, and endotracheal intubation with intermittent positive pressure respiration for acute pulmonary oedema or severe coma (A P Hall, unpublished). Corticosteroids are now agreed to be contraindicated in the management of falciparum malaria. ${ }^{5}$ The careful maintenance of fluid balance is of vital importance, since fluid overload may precipitate acute pulmonary oedema with its serious prognosis. $^{2}$

Malaria caused by some strains of $P$ falciparum acquired in areas where chloroquine resistance is prevalent, and especially in South East Asia, ${ }^{3}$ may recrudesce after initial response to quinine or, less often, to quinidine. ${ }^{10}$ This problem may be avoided by concluding treatment with either a single dose of the pyrimethamine-sulfadoxine combination Fansidar in countries where this remains effective $\mathrm{e}^{\mathrm{ls}}$ (Hall and Bhattacharya, unpublished) or a five to seven day course of tetracycline if resistance to this combination is present. ${ }^{16}$

Joint Director,
Public Health Laboratory Service Malaria Reference Centre,

W PETERS

London School of Hygiene and Tropical Medicine,

London WCIE 7HT

Consultant Physician,

A P HaLL

Hospital for Tropical Diseases,

London NW1 OPE

1 Gyr K, Speck B, Ritz R, Cornu P, Buckner CD. Zerebrale malaria tropical mit schwarzwasserfieber. Schweiz Med Wochenschr 1974;104:1628-30.

2 Hall AP. The treatment of severe falciparum malaria. Trans R Soc Trop Med Hyg 1977;71:367-79.

3 Chongsuphajaisiddhi T, Sabcharoen A, Attanath P. In vivo and in vitro sensitivity of falciparum malaria to quinine in Thai children. Ann Trop Paediatr 1981;1:21-6.

4 White NJ, Looareesuwan S, Warrell DA, et al. Quinine loading dose in cerebral malaria. Am $\mathcal{J}$ Trop Med Hyg 1983;32:1-5.

5 Warrell DA, Looareesuwan S, Warrell MJ, et al. Dexamethasone proves deleterious in cerebral malaria. A double blind trial in 100 comatose patients. N Englf Med 1982;306:313-9.
6 White NJ, Warrell DA, Chantavanich P, et al. Severe hypoglycemia and hyperinsulinemia in falciparum malaria. N Englf Med 1983;309:61-6.

7 White NJ, Warrell DA, Looareesuwan S, Chanthavanich P, Phillips RE, Pongpaew P. Pathophysiological and prognostic significance of cerebrospinal-fluid lactate in cerebral malaria. Lancet 1985; ; :776-8.

8 White NJ, Warrell DA, Looareesuwan S, et al. Hypoglycaemia in falciparum malaria. $Q \mathcal{J}$ Med 1982;51:508-9.

White NJ, Warrell DA. Clinical management of chloroquine-resistant Plasmodium falciparum malaria in Southeast Asia. Trop Doct 1983;13:153-8.

10 White NJ, Logresuwan S, Warrell DA, Chongsuphajaisiddhi T, Bunnag D, Harinasuta T. Quinidine in falciparum malaria. Lancet 1981 ;ii: 1069-71.

11 White NJ, Looareesuwan S, Warrell DA. Quinine and quinidine: a comparison of EKG effects during the treatment of malaria. $f$ Cardiovasc Pharmacol 1983;5:173-5.

12 Ris HB, Stahel E, Pittet JF, Friedmann M. Das Antiarrhythmikum Chinidin als Alternative in der Behandlung der schweren Falciparum-Malaria. Schweiz Med Wochenschr 1983;113:254-8.

13 Phillips RE, Warrell DA, White NJ, Looareesuwan S, Karbwang J. Intravenous quinidine for the treatment of severe falciparum malaria. Clinical and pharmacokinetic studies. $N$ Engl f Med 1985;312:1273-8

$14 \mathrm{Li} \mathrm{G}$, Arnold K, Guo X, Jian H, Fu L. Randomised comparative study of mefloquine, qinghaosu, and pyrimethamine-sulfadoxine in patients with falciparum malaria. Lancet 1984;ii: 1360-1.

15 Hall AP, Doberstyn EB, Mettaprakong V, Sonkom P. Falciparum malaria cured by quinine followed by sulfadoxine-pyrimethamine. Br Med f 1975;ii:15-7.

6 World Health Organisation. Advances in malaria chemotherapy. Report of a scientific group. Geneva: World Health Organisation, 1984. (WHO Tech Rep Ser, No 711.)

\section{Blood lead and blood pressure}

Exposure to lead and its possible effect on health has long been a topic of public and scientific concern. Much of this concern has focused on the contribution of leaded petrol to the total body content of lead and the possibility that moderate rises in body lead may affect the mental development of children. ${ }^{12}$ Concern has also been expressed about the link between exposure to lead and hypertension, even though no consistent relation has been shown in those who have been exposed to high concentrations of lead in an industrial setting. ${ }^{3}$ The hypothesis that hypertension may be causally related to raised blood lead concentrations has been supported by the fact that the solubility of lead is increased in soft, acidic water, that in areas where the water supply is soft the mortality rate from cardiovascular disease is increased, and that hypertension is a major contributor to cardiovascular mortality.

Glasgow was the centre for much of the early work on this subject, for the drinking water is extremely soft, lead plumbing systems are common, and there is a high prevalence of hypertension and a very high cardiovascular mortality rate. In 1972, in the suburb of Renfrew, 3001 men and women residents aged 45-64 were screened for hypertension (diastolic blood pressure greater than $100 \mathrm{~mm} \mathrm{Hg}$ ). ${ }^{4}$ Hypertension was present in 468 and the first 135 who attended a follow up clinic were matched for age and sex with 135 normotensive people randomly selected from the same population. Mean blood lead concentrations were higher in the hypertensive group, in whom concentrations greater than $2 \mu \mathrm{mol} / 1(41 \mu \mathrm{g} / 100 \mathrm{ml})$ occurred more frequently. In a paired analysis of hypertensive and normotensive men $(n=74)$, using three categories of blood lead concentration, there were more pairs in which the hypertensive man had a higher blood lead concentration. A similar analysis for women gave results that were not statistically significant. The authors concluded that high blood pressure in the west of Scotland "is associated with high blood lead levels, which might explain the high prevalence of cardiovascular disease in the area." When this study was carried out the important influences of alcohol and smoking on blood lead were not known, ${ }^{5}$ nor was there an awareness of the effects of alcohol on blood pressure. ${ }^{6}$ Thus it is possible that the higher blood lead concentrations in the hypertensive subjects were due to 